\title{
A Study on Mechanical Properties of Modified Alumina/Allylester Composites
}

\author{
Jyongsik JANG and Jieun YI
}

\author{
Department of Chemical Technology, College of Engineering, Seoul National University, \\ San 56-1, Shinlimdong, Kwanakgu, Seoul 151-742, Korea
}

(Received November 16, 1995)

\begin{abstract}
The mechanical properties of allylester composites filled with surface modified alumina have been studied with variation of the type of silane coupling agents. We investigated the tensile modulus, the compressive modulus and strength, and the flexural modulus and yield strength of each system as a function of the concentration of silane coupling agent using an Universal Testing Machine (UTM). At optimum concentration of each silane coupling agent, the tensile, compressive, flexural properties showed the maximum values. The relationships between the mechanical properties and the concentration of each silane coupling agent have been studied. In addition, the effect of silane coupling agent on each mechanical property was observed.

KEY WORDS Allylester Composites / Tensile Property / Compressive Property / Flexural Property /

Alumina /
\end{abstract}

Allylester resin has many advantages, including a range of mechanical properties, long shelf-life, and thermal stability, because it is cured after preparation of prepolymer by transesterification, differently from other allyl system polymers. ${ }^{1-4}$ Besides, it has weathering stability, chemical resistance, heat resistance, corrosion resistance, distinguished optical properties, and excellent electric resistance at elevated temperature and high humidity. Therefore, allylester resin can be widely used in many applications such as optical material, building material, artificial marble, circuit board, and so forth. ${ }^{5-8}$

Especially, as the prepolymerization is accomplished not by radical reaction but by transesterification, it is easy to change the content and variety of polyol and diallyl ester. It is also easy to modify the molecular structure and performance of the polymer at will.

It takes too long time in curing the system completely and that is pointed out as weakness of allylester resin. It is, however, expected there can be possibility of some applications to the new processing which is unable as before. Their utilities lie in the extremely wide variety of chemical reactions that can be used for the curing and the many different properties that result. On the other hand, the applications of allylester resins are restricted due to the limited information concerning the cure kinetics of reinforced as well as pristine allylester resins, the mechanical-thermal behaviors, and the mechanical properties of them though a good many studies on other resins have been achieved. ${ }^{9-14}$

In an effort to achieve better end-use properties of composites, one inevitably uses reinforcements such as inorganic fibrous materials and fillers such as particulates. Fillers are added to thermoset polymeric matrix for one or more of the following reasons: reduce cost, increase stiffners, reduce mold shrinkage, control viscosity, and produce smoother surface. Although fillers increase the modulus of composites, they tend to reduce its strength and impact resistance. ${ }^{15}$ Many reinforced composite materials offer a combination of strength and modulus that are either comparable to or better than many traditional metallic materials. Because of their low specific gravities, the strength-weight ratios, and modulus-weight ratios of these composite materials are markedly superior to those of metallic materials. For these reasons, fiber-reinforced composites have emerged as a major class of structural material and are either used or being considered as substitutions for metals in many weight-critical components in automotive and other industries. Coefficients of thermal expansion for many reinforced composites are much lower than those for polymers. As a result, composite structures may exhibit a better dimensional stability over a wide temperature range. However, the differences in thermal expansion between polymers and composite materials may create undue thermal stresses when they are used in conjunction, for example, near an attachment. ${ }^{15}$ An advantage attributed to reinforced polymers is their noncorroding behavior. However, many polymeric matrix composites are capable of absorbing moisture from the surrounding environment, which creates dimensional changes as well as adverse internal stresses within the materials. If such behavior is undesirable in an application, the composite surface must be protected from moisture diffusion by appropriate paints or coatings. Among the other environmental factors that may cause degradation in the mechanical properties of some polymeric matrix composites are elevated temperatures, corrosive fluids, and ultraviolet rays. ${ }^{15}$

Unlike thermoplastic composites, the curing of thermosetting resins can be influenced by reinforcements and fillers. ${ }^{16,17}$ It is important to verify the cure kinetics of reinforced allylesters for the various applications of this allylester. Therefore, we have already achieved studies on cure kinetics of alumina reinforced allylester composites as well as pristine allylester polymers. ${ }^{17,18}$ In addition, we have studied some mechanical-thermal behaviors of allylester polymers and composites filled with alumina using the dynamic mechanical thermal analysis. ${ }^{19,20}$ Besides, we have already investigated some mechanical properties of allylester prepolymers, cured polymers, and alumina reinforced allylester composites. $^{21}$ Now, we have a desire to investigate some mechanical properties of allylester composites reinforced with surface modified alumina. 
The interfacial adhesion between matrix and filler has been known as a major factor which determined the mechanical properties of the polymer composites, and it became more important under hot/wet conditions. ${ }^{22}$ In general, thermoset polymer composites have poor adhesion at the interface between matrix and filler. To improve the interfacial adhesion, various techniques of surface treatment of filler have been studied. ${ }^{23-26}$ Among them, silane coupling agents are famous for the adhesion promoter of the polymer composites interface. Some studies have been reported on the increases of the mechanical properties of the composites using silane coupling agents. ${ }^{27-32}$

In order to increase compatibility between the particulates and the matrix resin, the surface of alumina was modified with following silane coupling agents: 3-methacryloxypropyltrimethoxysilane (MPS), 3-aminopropyltriethoxysilane (APS), (3-glycidoxypropyl) trimethoxysilane (GPS), and vinyltrimethoxysilane (VTS). It is rationalized that the type of chemicals applied for surface treatment is usually proprietary. ${ }^{33,34}$

A little information has been reported that discussed the effect of silane coupling agents on the mechanical properties of composites. However, a thorough understanding of the relationships among the fillers, the silane coupling agent, and the matrix is the key to successful fabrication of composites.

The ultimate goals of this study are to improve the mechanical properties of alumina reinforced composites by surface modification and to obtain some parameters of the mechanical properties of them. This study also attempted to investigate the change in the mechanical parameters as a function of the concentration of each silane coupling agent, to study relationships between the surface treatment of alumina and the mechanical properties, and to find optimum concentrations of each silane coupling agent for the highly improved mechanical properties.

\section{EXPERIMENTAL}

\section{Materials}

Diallyl monomers used in this study were diallyl terephthalate (DAT) and diallyl isophthalate (DAIP) supplied by Daiso, Japan. 1,3-butylene glycol (1,3-BG) and diethylene glycol (DEG) purchased from Junsei Chemical Co., Ltd. and Duksan Pharmaceutical Co., Ltd., respectively, were used as diols for transesterification. Monobutyltin oxide (MBO) was used as the catalyst and dicumyl peroxide (DCP) as the curing agent in this research. Alumina purchased from Showa Denko, Co., Japan was employed as the filler. Tables I and II show the chemical structures of the materials used in this study.

The following silane coupling agents were applied for surface treatment of alumina: 3-methacryloxypropyltrimethoxysilane (MPS), 3-aminopropyltriethoxysilane (APS), (3-glycidoxypropyl)trimethoxysilane (GPS), and vinyltrimethoxysilane (VTS). These four silanes were purchased from Petrarch Systems, Inc. Table III shows the chemical structures of four silane coupling agents used in this study.
Table I. Chemical structures of momomers used for preparation of allylester prepolymers in this study

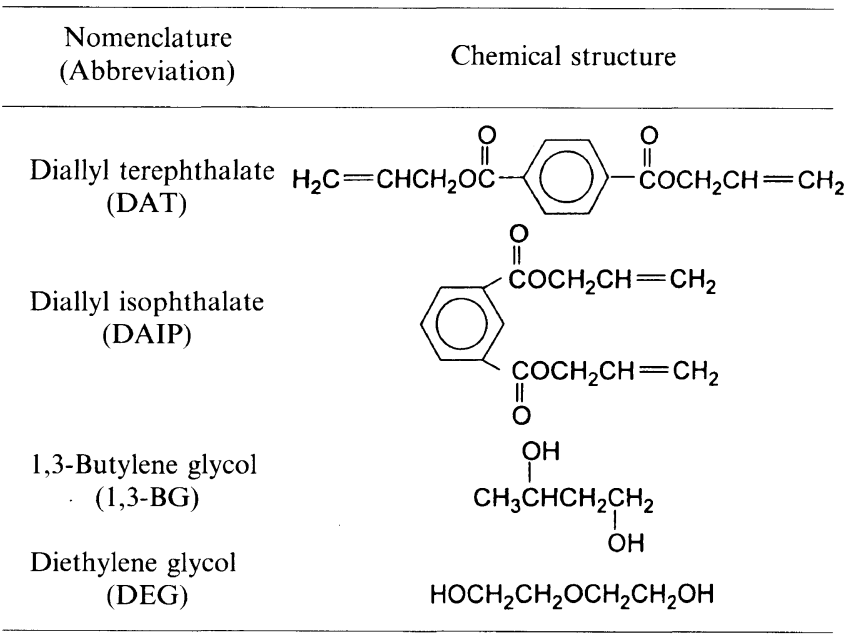

Table II. Chemical structures of curing agent (DCP) and catalyst (MBO) used in this study

\begin{tabular}{c}
$\begin{array}{c}\text { Nomenclature } \\
\text { (Abbreviation) }\end{array}$ \\
$\begin{array}{c}\text { Dicumyl peroxide } \\
\text { (DCP) } \\
\text { Monobutyltin oxide } \\
\text { (MBO) }\end{array}$ \\
\hline
\end{tabular}

Table III. Chemical structures of silane coupling agents used for treatment of alumina in this study

Nomenclature (Abbreviation) Chemical structure

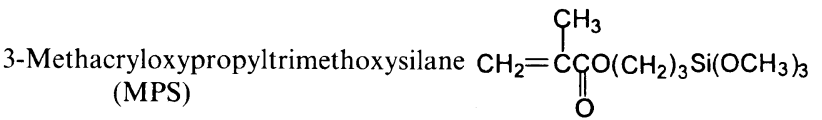

3-Aminopropyltriethoxysilane $\mathrm{H}_{2} \mathrm{NCH}_{2} \mathrm{CH}_{2} \mathrm{CH}_{2} \mathrm{Si}\left(\mathrm{OC}_{2} \mathrm{H}_{5}\right)_{3}$ (APS)

(3-Glycidoxypropyl)trimethoxysilane $/ \mathrm{CH}_{2}-\mathrm{O}-\left(\mathrm{CH}_{2}\right)_{3} \mathrm{Si}\left(\mathrm{OCH}_{3}\right)_{3}$ (GPS)

Vinyltrimethoxysilane (VTS)

$\mathrm{CH}_{2}=\mathrm{CH}-\mathrm{Si}\left(\mathrm{OCH}_{3}\right)_{3}$

\section{Synthesis, Treatment of Alumina, and Preparation of} Samples

Three kinds of prepolymer were prepared from DAT + 1,3-BG, DAIP + 1,3-BG, and DAIP + DEG. Preparation method of prepolymers was identical with the previous papers. ${ }^{20,21} \mathrm{We}$ used DAT $+1,3-\mathrm{BG}$ prepolymer as a matrix resin in this research.

Silane coupling agents were hydrolyzed in ethanol/ water $(70 / 30)$ solution with trace acetic acid at $\mathrm{pH} 3.5$ for 1 hour. Then alumina was immersed in the silane solution and dried at room temperature for 7 days. ${ }^{35}$ Alumina was treated with various silane coupling agents (MPS, APS, GPS, and VTS) and concentrations (0.1- 
Table IV. The dimension of all the samples for the mechanical tests using UTM

\begin{tabular}{|c|c|c|c|c|c|c|c|c|c|c|c|c|c|c|}
\hline \multirow{2}{*}{$\begin{array}{l}\text { Class of test } \\
\text { Symbol }\end{array}$} & \multicolumn{8}{|c|}{ Tensile test } & \multicolumn{3}{|c|}{ Compressive test } & \multicolumn{3}{|c|}{ Flexural test } \\
\hline & $L_{\mathrm{o}}$ & $D$ & $L$ & & $W_{\mathrm{o}}$ & $W$ & $T$ & $R$ & $L$ & $W$ & $T$ & $L$ & $T$ & $W$ \\
\hline Length/mm & & 85 & 57 & 35 & 19 & 6.0 & 3.5 & 14 & 9.0 & 6.0 & 3.5 & 16 & 3.5 & 6.0 \\
\hline
\end{tabular}

a See the Figure 1 for the symbols. $R$, the radius of curvature.

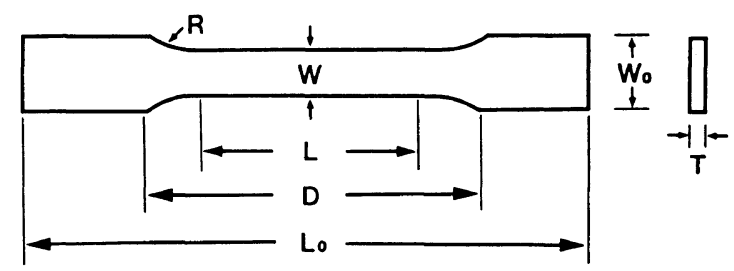

(A)
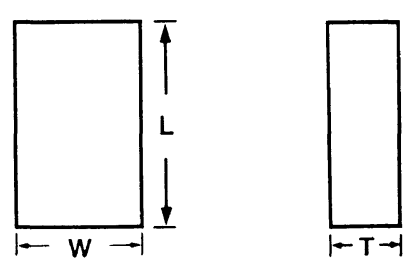

(B)

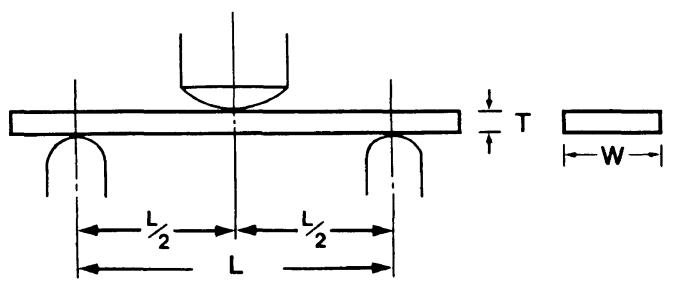

(C)

Figure 1. The schematic illustrations of each specimens used in the test of mechanical properties: Tensile test (A), compressive test (B), and flextural test (C).

$0.5 \mathrm{wt} \%$ ). All the samples contained $2 \mathrm{phr}$ DCP and $20 \mathrm{phr}$ modified alumina were cured in $130^{\circ} \mathrm{C}$ for 18 hours. The molds were made by silicon rubber in the shape of Figure 1. All the dimensions of samples were atrranged in Table IV. The symbol, $R$ is the radius of curvature.

\section{Test of Mechanical Properties}

The tensile, compressive, and flexural properties were measured by a Universal Testing Machine (Instron 4201). The measurements of the tensile, compressive, and flexural tests were performed according to ASTM D 638, D 695, and D 790, respectively. ${ }^{36-38}$ The capacity of load-cell used in each test was $5 \mathrm{kN}$. Crosshead speeds were $1 \mathrm{~mm} \mathrm{~min}^{-1}$ in tensile and flexural tests and $0.5 \mathrm{~mm} \mathrm{~min}^{-1}$ in compressive test. Seven specimens were used for each mechanical test.

\section{RESULTS AND DISCUSSION}

In general, mechanical properties of polymer compos-

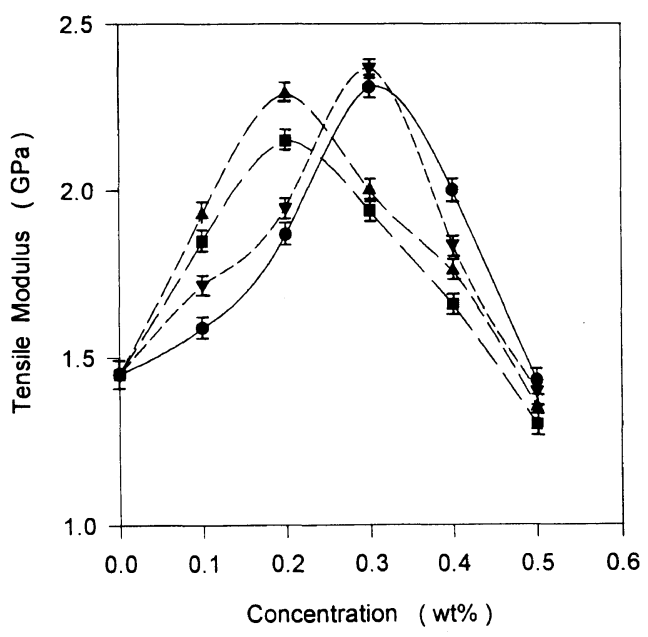

Figure 2. The tensile modulus of DAT $+1,3-\mathrm{BG} / 20 \mathrm{phr}$ modified alumina composites as a function of the concentration of each silane coupling agent: MPS $(\mathbf{O})$, APS $(\boldsymbol{\square})$, GPS $(\boldsymbol{\Delta})$, and VTS $(\boldsymbol{\nabla})$ at the crosshead speed, $1.0 \mathrm{~min} \mathrm{~min}^{-1}$.

ite depend on the concentration of silane coupling agent.

Whereas low concentration of silane on the reinforcement forms chemisorbed layer, high coverage silane may form chemisorbed and physisorbed layer on the reinforcement. ${ }^{39,40}$

Figure 2 shows the tensile modulus as a function of the concentration of each silane coupling agent. In the case of MPS ( $)$ and VTS ( $\boldsymbol{\nabla}$ ) modified systems, the optimum concentration appeared at $0.3 \mathrm{wt} \%$. The maximum improvements were $66 \%$ and $59 \%$, respectively. The tensile modulus of untreated system was $1.45 \mathrm{GPa}$. As the concentration of coupling agent increased, the tensile modulus increased until $0.3 \mathrm{wt} \%$. After this concentration, the tensile modulus decreased with increasing the concentration of silane. This result comes from the effect as a diluent or lubricant when the coupling agent is introdeuced in excess. ${ }^{14,41}$ Excess silane acts as a lubricant, which can form the weak boundary under the load. In the case of APS ( $\boldsymbol{\square}$ ) and GPS ( $\boldsymbol{\Delta})$ modified systems, the optimum concentration lay $0.2 \mathrm{wt} \%$. The maximum improvments were $48 \%$ and $58 \%$, respectively.

These optimum concentrations correspond to the results of DMTA. That is, the optimum concentrations in the tensile modulus match with those of the maximum glass transition temperatures. It can be said that the maximum crosslinking reaction occurred in curing at optimum concentrations of silane coupling agents in each system and the maximum glass transition temperature and tensile modulus appeared at the same concentrations. The maximum values of tensile moduli in MPS and VTS modified systems were higher than those in APS and GPS modified systems. This is due to the fact that MPS 


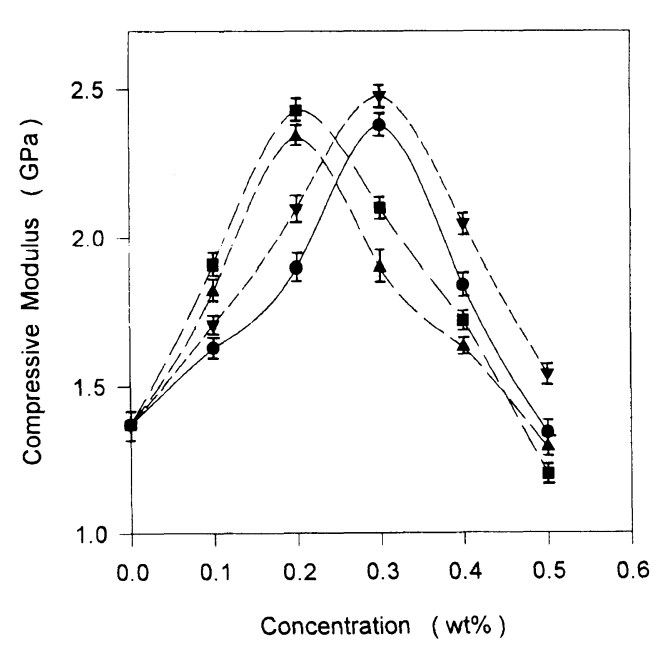

Figure 3. The compressive modulus of DAT $+1,3-\mathrm{BG} / 20 \mathrm{phr} \bmod -$ ified alumina composites as a function of the concentration of each

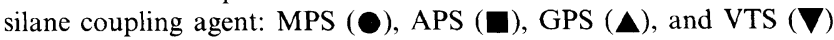
at the crosshead speed, $0.5 \mathrm{~min} \mathrm{~min}^{-1}$.

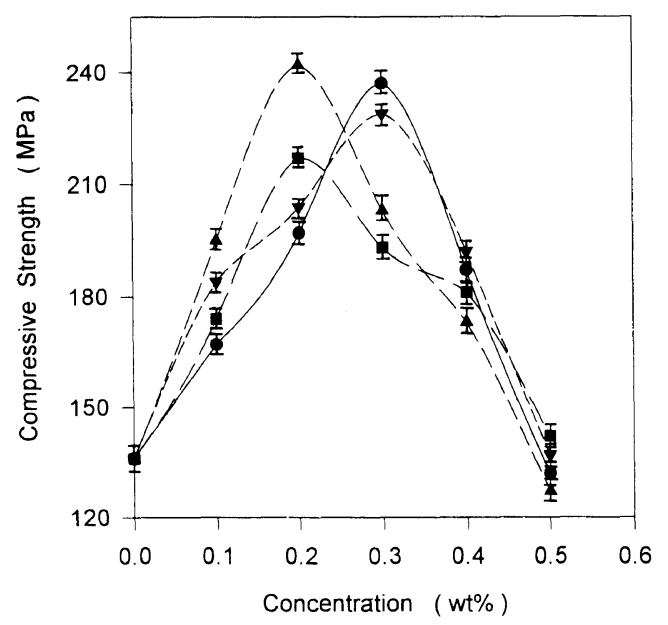

Figure 4. The compressive strength of DAT $+1,3-\mathrm{BG} / 20 \mathrm{phr}$ modified alumina composites as a function of the concentration of each

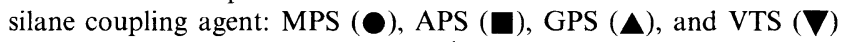
at the corsshead speed, $0.5 \mathrm{~min} \mathrm{~min}^{-1}$.

and VTS are reactive silane coupling agents which contain double bonds but APS and GPS are nonreactive ones which have no double bonds.

Figure 3 represents the compressive modulus with the variation of the concentrations of each silane coupling agent. The maximum compressive modulus appeared at $0.3 \mathrm{wt} \%$ in MPS and VTS modified systems and $0.2 \mathrm{wt} \%$ in APS and GPS modified systems, respectively. The maximum improvements showed up in the range, $70-85 \%$. The improvement of the compressive moduli was larger than that of the tensile moduli. In addition, there existed little differences in the maximum values of compressive moduli of each system, comparing with those in the maximum values of tensile moduli. In general, the flexural property is the combination of the tensile and compressive properties. At this point, tensile property does not have the direct relationship with compressive property, but have the partial relationship with the flexural property. Therefore, it may be concluded that the effect of silane coupling agent is larger for the compressive property than for the tensile property and the type of silane coupling agent is more important in

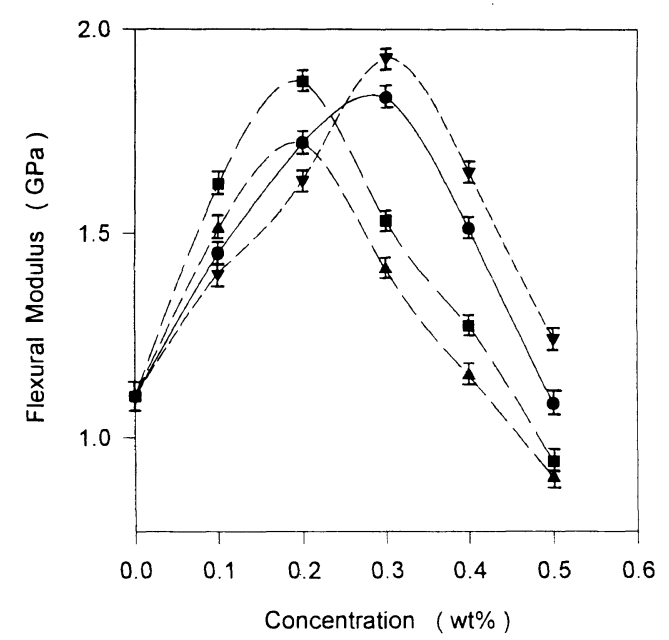

Figure 5. The flexural modulus of DAT $+1,3-\mathrm{BG} / 20 \mathrm{phr}$ modifed alumin composites as a function of the concentration of each silane coupling agent: MPS ( $\boldsymbol{\bullet})$, APS ( $\boldsymbol{\square})$, GPS $(\boldsymbol{\Delta})$, and VTS $(\boldsymbol{\nabla})$ at the crosshead speed, $1.0 \mathrm{~min} \mathrm{~min}^{-1}$.



Figure 6. The flexural yield strength of DAT $+1,3-\mathrm{BG} / 20 \mathrm{phr}$ modified alumina composites as a function of the concentration of

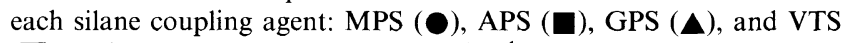
(V) at the crosshead speed, $1.0 \mathrm{~min} \mathrm{~min}^{-1}$.

the tensile modulus than in the compressive modulus.

Figure 4 shows the compressive strength as a function of the concentration of each silane coupling agent. The maximum compressive strengths appeared at $0.3 \mathrm{wt} \%$ in MPS and VTS modified systems and $0.2 \mathrm{wt} \%$ in APS and GPS modified systems. The maximum improvements turned up in the range, $63-78 \%$.

Figure 5 represents the flexural modulus with the variation of the concentrations of each silane coupling agent. The maximum flexural moduli showed up at $0.3 \mathrm{wt} \%$ in MPS and VTS modified systems and $0.2 \mathrm{wt} \%$ in APS and GPS modified systems, respectively, similar to the case of tensile and compressive test since the flexural property is the combination of the tensile and compressive properties. The maximum improvements appeared in the range, $58-77 \%$.

Figure 6 shows the flexural yield strength as a function of the concentration of each silane coupling agent. The maximum flexural yield strengths appeared at $0.3 \mathrm{wt} \%$ in MPS and VTS modified systems and $0.2 \mathrm{wt} \%$ in APS and GPS modified systems similar to the case of tensile and compressive test. The maximum improve- 
ments turned up in the range, $50-65 \%$. The maximum values of flexural yield strength in MPS and VTS modified systems were higher than those in APS and GPS modified systems. Thus, it can be considered that the tensile property has more influence on the flexural property than the compressive property has in these systems.

When the silane coupling agents are untroduced onto the alumina surface in allylester composites, two interfaces exist between filler and allylester polymer matirx -the interface between alumina and silane coupling agents and the interface between silane coupling agents and allylester polymer matrix. At the interface between alumina and silane coupling agents, the hydroxyl groups of the silanes and those of the filler surface can react with each other by siloxane bond or hydrogen bond formation. The interfacial adhesion can be promoted by this mechanism. ${ }^{22}$ At the interface between silane coupling agents and matrix, three representative mechanisms of the adhesion promotion are known. First, silane coupling agents react chemically with polymer matrix at the molding temperature and the interfacial adhesion can be strengthened. Interpenetrating polymer network theory is regarded as another mechanism of the adhesion promotion. This network is formed through the interdiffusions of matrices and silanes in the interphase. At high temperature in the composites manufacturing cycle, the silane coupling agents on the alumina surface diffuse into polymer matrix phase and act as the partial solvent of the polymer matrix in the vicinity of alumina surface. However, as the composites cool, the polymer loses its solubility and separates as an interpenetrating phase with the siloxane at the interphase of the composites. Finally, the compatibility of the silane coupling agents with polymer matrix is a factor to determine the interfacial adhesion strength between the silanes and polymer matrix. ${ }^{14}$

\section{CONCLUSION}

From the study on mechanical properties of allylester composites filled with modified alumina, it can be concluded that,

1. In the case of MPS and VTS modified systems, the optimum concentration of the tensile, compressive, and flexural properties appeared at $0.3 \mathrm{wt} \%$ which coincided with that of the maximum glass transition temperature.

2. In the case of APS and GPS modified systems, the optimum concentration of the tensile, compressive, and flexural properties showed up at $0.2 \mathrm{wt} \%$ which corresponded to that of the maximum glass transition temperature.

3. The maximum values of tensile moduli in MPS and VTS modified systems were higher than those in APS and GPS modified systems.

4. The effect of silane coupling agent was larger for the compressive property than for the tensile property and the type of silane coupling agent was more important in the tensile modulus than in the compressive modulus.

5. The tensile property has more influence on the flexural property than the compressive property has in surface modified alumina filled allylester composites.

\section{REFERENCES}

1. A. Matsumoto, M. Miyagawa, M. Yamawaki, and M. Oiwa, $J$. Polym. Sci., Polym. Lett. Ed., 24, 7 (1986).

2. A. Matsumoto, Y. Ogasawara, S. Nishikawa, T. Aso, and M. Oiwa, J. Polym. Sci., Part A, Polym. Chem., 27, 839 (1989).

3. A. Matsumoto, M. Miyagawa, M. Yamawaki, and M. Oiwa, $J$. Appl. Polym. Sci., 29, 2241 (1984).

4. Y. Ohtsuka, H. Kawaguchi, and T. Hamasaki, J. Appl. Polym. Sci., 27, 1771 (1982).

5. C. E. Schildknecht, "Allyl Compounds and Their Polymers," John Wiley \& Sons, New York, N.Y., 1973, Chapters 11 and 12.

6. T. Whelan and J. Goff, "Molding of Thermosetting Plastics," Van Nostrand Reinhold, New York, N.Y., 1990, pp 26-32.

7. ASTM D 1636-81, pp 29-33 (1987)

8. ASTM D 3027-72 (Reapproved 1981), pp. 735-736 (1987).

9. D. Lee and C. D. Han, J. Appl. Polym. Sci., 33, 419 (1987).

10. K. Lem and C. D. Han, J. Appl. Polym. Sci., 28, 3185 (1983).

11. L. W. Crane, P. J. Dynes, and D. H. Kaelble, Polym. Lett. Ed., 11, 533 (1973)

12. J. Shieh and T. J. Hsu, Polym. Eng. Sci., 32, 335 (1992).

13. E. L. Rodriguez, Polym. Eng. Sci., 31, 1022 (1991).

14. E. P. Plueddemann, "Silane Coupling Agents," Plenum Press, New York, N.Y., 1982, Chapters 4 and 7.

15. P. K. Mallick, "Fiber-Reinforced Composites, " Marcel Dekker Inc., New York, N.Y., 1988, Chapter 2.

16. J. D. Muzzy and A. O. Kays, Polym. Composites, 5, 169 (1984).

17. J. Jang and J. Yi, Polym. Eng. Sci., 35, 1583 (1995).

18. J. Jang and J. Yi, Polym. J., 27, 404 (1995).

19. J. Jang and J. Yi, A dynamic mechanical thermal analysis of allylester polymers and composites filled with alumina, J. Appl. Polym. Sci., submitted.

20. J. Jang and J. Yi, A dynamic mechanical thermal analysis on surface modified alumina filled allylester composites, J. Appl. Polym. Sci., submitted.

21. J. Jang and J. Yi, A study on mechanical properties of allylester composites filled with alumina: I. Unmodified system, Polym. J., submitted.

22. H. Ishida and J. L. Koenig, Polym. Eng. Sci., 18, 128 (1978).

23. J. B. Donnet and G. Guilpain, Carbon, 27, 749 (1989).

24. N. Menon, F. D. Blum, and L. R. Dharani, J. Appl. Polym. Sci., 54, 113 (1994)

25. L. Y. Yuan, S. S. Shyu, and J. Y. Lai, J. Appl. Polym. Sci., 42, 2525 (1991).

26. C. D. Han, C. Sandford, and H. J. Yoo, Polym. Eng. Sci., 18 849 (1978).

27. L. J. Broutman, 25th Annual Technical Conference Reinforced Plastics/Composites Division, Society of Plastics Industry (SPI), Inc., Washington D.C., January 27-30, 1970.

28. H. Ishida and K. Nakada, 42nd Annual Conference on Composites Institute, Society of Plastics Industry (SPI), Inc., Cincinnati, OH, February 2-6, 1987.

29. J. L. Koenig and H. Emadipour, Polym. Comosites, 6, 142 (1985)

30. E. P. Plueddemann, 39th Annual Conference Reinforced Plastics/Composites Institute, Society of Plastics Industry (SPI), Inc., New York, N.Y., January 16-19, 1984.

31. E. P. Plueddemann and G. L. Stark, 35th Annual Technical Conference Reinforced Plastics/Composites Division, Society of Plastics Industry (SPI), Inc., Washington, D.C., 1980.

32. H. Ishida and J. L. Koenig, J. Collect. Interface Sci., 64, 565 (1978).

33. D. F. Sounik and M. E. Kenny, Polym. Composites, 6, 151 (1985).

34. M. Y. Boluk and H. P. Schreiber, Polym. Composites, 7, 295 (1986).

35. R. Yosomiya, K. Morimoto, A. Nakajima, Y. Ikada, and T. Suzuki, Ed., "Adhesion and Bonding in Composites," Marcel Dekker Inc., New York, N.Y., 1989, Chapters 3, 5, and 11.

36. ASTM D 638M-84, pp 227-238 (1987)

37. ASTM D 695M-85, pp 277-284 (1987).

38. ASTM D 790M-86, pp 398-410 (1987).

39. C. Scott, H. Ishida, and F. H. J. Maurer, in "Composite Interfaces," H. Ishida and J. L. Koenig, Ed., Elsevier Science, New York, N.Y., 1986, p 177.

40. N. Ikuta, H. Hamada, and H. Ichihashi, Composite Interfaces, 1, 455 (1993).

41. J. Jang, Ph. D. Dissertation, Case Western Reserve University, Cleveland, $\mathrm{OH}, 1988$. 